\title{
Salud, vida plena, salvación: miradas ecoteológicas
}

\begin{abstract}
Resumen
El presente trabajo propone una reflexión ecoteológica sobre los conceptos de salud y salvación con el propósito de orientar acciones para el cuidado de la vida en todas sus manifestaciones. Para ello se sigue un análisis bíblico y teológico que va conectando la salud humana con la salud ambiental, mostrando el carácter indisoluble de estos ámbitos de la mano de una hermenéutica bíblica que relaciona la ecología con la soteriología. Una teología de la salvación tendrá que ser necesariamente una ecoteología que permita redescubrir en la fe elementos ecológicos que favorezcan una sana y equilibrada interrelación entre Dios, la humanidad y el resto de la creación.
\end{abstract}

Palabras-clave: salud, salvación, ecología, Biblia, vida

\begin{abstract}
The present work proposes an ecotheological reflection on the concepts of health and salvation with the purpose of guiding actions for the care of life in all its manifestations. This is followed by a biblical and theological analysis that connects human health with environmental health, showing the indiscriminate character of these areas within the scope of a biblical hermeneutic that relates ecology to soteriology. A theology of salvation will necessarily have to be an ecotheology that will allow us to rediscover in the ecological elements that favor a healthy and balanced interrelationship between God, humanity and the rest of creation.
\end{abstract}

Keywords: health, salvation, ecology, Bible, life

\section{Introducción}

La salud y la enfermedad son dos realidades que afectan al ser humano en su totalidad. Ambas están íntimamente relacionadas en las distintas dimensiones que componen la persona y la relación de esta con su entorno. La enfermedad es una experiencia que desestructura, que

\footnotetext{
${ }^{1}$ Amós López Rubio es pastor de la Fraternidad de Iglesias Bautistas de Cuba y Doctor en Teología por el ISEDET. Es autor de artículos y libros con énfasis en Teología Pastoral, protestantismo en Cuba y ecumenismo.
} 
altera globalmente el sentido mismo de la existencia, pues supone una ruptura fundamental en el flujo de la vida porque conlleva dependencia, aislamiento y sufrimiento. Los seres humanos adquirimos conciencia de la salud a través de la enfermedad, de la alegría a través de la tristeza, de la vida a través de la muerte.

La Organización Mundial de la Salud ha declarado que la salud no es mera biología, sino vida de calidad, entendiendo esto último como capacidad y posibilidad de realización personal. La salud puede ser considerada como un estado de equilibrio no solamente físico, sino también psíquico y espiritual. Es uno de los anhelos y de los derechos más esenciales del ser humano y constituye la condición previa para poder satisfacer cualquier otra necesidad o aspiración de bienestar y felicidad. La buena salud contribuye a la humanización de la vida. Ello implica el desarrollo de las facultades intelectuales, la sensibilidad afectiva y la posibilidad de elegir y afirmar determinados valores (Duarte, 2012).

Por lo cual, la comprensión actual de la salud va más allá de la noción tradicional que la comprende como ausencia de enfermedad. Cada vez gana más terreno una concepción holística de la salud que proporciona una visión integral del ser humano relacionando su cuerpo, su mente y su espíritu. En ese sentido, Roberto Swetsch, pastor y teólogo luterano del Brasil señala que la fragmentación del ser humano permitió un mejor conocimiento de las partes que lo componen pero no proporcionó una visión unificada y abarcadora del sentido de su vida. De ahí que hoy se busque comprender la vida humana desde distintas visiones que interactúan entre sí: antropológica, médica, filosófica y también teológica. En esta perspectiva "la salud significa integridad o integralidad y no apenas ausencia de enfermedad. Tal comprensión apunta hacia las distintas dimensiones de la personalidad como la física, la emocional, la espiritual y la social, como dimensiones que interactúan solidariamente" (Zwetsch, 2003, pp. 45-46).

La salud es la condición de posibilidad que permite la realización del potencial humano de cualquier persona. No basta tener un cuerpo vigoroso o saludable, es preciso vivir a gusto con él. No es suficiente sentirse útil y tener una dedicación o trabajo, es necesario realizar una misión en la vida. Salud es aquella manera de vivir autónoma, solidaria y alegre que se da cuando se va asumiendo la propia realización.

Las crisis económicas, el deterioro del medio ambiente, los desplazamientos de poblaciones, los fenómenos migratorios, la pobreza, el desempleo, la falta de acceso a la educación y otros servicios básicos así como la violencia de género, entre otras situaciones, son factores de riesgo que afectan las condiciones y calidad de vida de las personas. En el cuidado de la salud se hace necesario recrear la espiritualidad desde una perspectiva integral que incluye lo pastoral, social, ambiental desde 
un enfoque de derecho, donde la salud es un derecho inalienable del ser humano. La dimensión espiritual de la vida hace referencia a lo esencial de los valores y a la fuerza animadora de los seres humanos. Es una fuerte conexión entre las personas, la naturaleza y el mundo (Duarte, 2012, 101).

En situaciones de enfermedad, se levantan preguntas importantes para la vida, preguntas que nos han acompañado como seres humanos a través de la historia, preguntas que también abren nuevos horizontes a la fe y a la manera de comprender a Dios en medio del dolor y el sufrimiento, preguntas que también demandan respuestas de las iglesias para revisar de qué manera están llevando adelante el ministerio sanador del evangelio.

\section{Algunas visiones bíblico-teológicas sobre salud-enfermedad}

En la Biblia encontramos diferentes maneras de comprender la experiencia de la enfermedad y la salud. En el Antiguo Testamento, la salud es uno de los componentes de la shalom de Dios, un estado de paz, bienestar, justicia y vida plena para la comunidad. La enfermedad, en cambio, es entendida como cansancio, falta de vitalidad. En términos generales, la enfermedad es interpretada como castigo de Dios por el pecado. Estar enfermos es estar en des-gracia, alejado de la gracia y la bondad de Dios, abandonado a su suerte. Recordemos solamente el caso de las personas enfermas de lepra: sufrían una doble exclusión, lejos de Dios y lejos de la comunidad (Lv 13, 45-46). Varios textos proféticos utilizan la imagen de la recuperación de la salud para señalar la restauración del pueblo que se ha alejado de Dios (Is 33, 24; Jr 33, 4-7).

Sin embargo, el libro de Job ofrece una alternativa a esta idea de que las enfermedades son la consecuencia del pecado. Job afirma que los malvados viven una larga vida y los buenos son alcanzados por la enfermedad y el sufrimiento, al tiempo que rechaza el carácter hereditario del pecado: "Se dice que Dios hace pagar a los hijos por las faltas de los padres. Pero es el propio malvado quien debe pagar y escarmentar" (Jb 21, 19).

Por su parte, Jesús nos ofrece otra mirada. Recordamos el relato del ciego de nacimiento y la pregunta de los discípulos: ¿Quién pecó para que este naciera ciego, él o sus padres? Y Jesús respondió: “Ni por su propio pecado ni por el de sus padres; fue más bien para que en él se demuestre lo que Dios puede hacer" (Jn 9). La comprensión que Jesús tiene de la enfermedad no es moralista sino compasiva: la sanidad es un signo de la misericordia de Dios y una manifestación de la llegada de su reino.

Tanto la historia de Job como la práctica sanadora de Jesús nos muestran, por un lado, que el sentido de la enfermedad no puede relacionarse con un esquema de culpa y castigo; $y$, por el otro, nos presenta a un Dios que es misericordia y que no nos abandona en el momento del sufrimiento. Es un Dios que nos acompaña y sufre con nosotros. Un Dios 
que tanto en la sanidad como en la no sanidad se revela como amor y compasión. Jesús tampoco llama la atención sobre sí mismo como sanador sino que remite a Dios, apunta hacia la gloria de Dios. De este modo, la fe cristiana, sin negar la realidad del sufrimiento afirma la presencia solidaria de Dios en medio del dolor.

En la carta de Santiago, se afirma que el sufrimiento nos puede llevar a la perfección y a la madurez, sirve como disciplina y corrección, lo cual no debe confundirse con castigo (St 1, 3-6). En el esquema apocalíptico el sufrimiento es más comunitario. Los sufrimientos surgen como consecuencia de la persecución, por resistir a las fuerzas que se oponen al reino de Dios y su justicia. Por eso es posible el gozo aún en medio de la tribulación (Ap 7, 9-17).

En las cartas de Pablo encontramos otra comprensión: la iglesia participa en los sufrimientos de su Señor. Tiene una perspectiva cristocéntrica y eclesial. La comunidad comparte el destino de Cristo por compartir la misma fe, así también se comparte la misma esperanza y el mismo consuelo: "si padecemos con Cristo, resucitaremos con él" (Ro 8, 17). Sufrir no implica la separación de Dios (Ro 8, 35-39). El sufrimiento no implica ausencia de salvación, ni se transfiere el alivio al futuro. La enfermedad no es deseable ni agradable, pero Dios puede transformar la adversidad en motivo de crecimiento (Ro 8, 28). Compartimos el dolor y la alegría de la vida en el ámbito solidario de la comunidad de fe.

\subsection{Recuperemos historias de sanidad y salvación}

Después de este breve repaso de algunas concepciones sobre salud y enfermedad, les invito a recuperar algunas historias en la Biblia donde encontramos experiencias sanadoras y salvíficas, buscando en ellas mensajes y llamados a nuestras iglesias de hoy en el camino y el desafío de ser comunidades de sanación, reconciliación y vida.

En el libro segundo delos Reyes encontramoslahistoria dela sanación de Naamán, el oficial asirio. Esta narración resalta el protagonismo de una niña esclava. Ella habla de Dios e indica el camino para que Naamán sea curado de su lepra por el profeta Eliseo. En una actitud amorosa y diaconal, ella intercede por aquel que la había hecho esclava. El texto nos dice que Dios se preocupa por nuestra salud, provee personas y conocimientos para aliviar y curar la enfermedad, para entender lo que nos sucede, asumirlo y superarlo. El Génesis afirma que toda persona ha sido creada a imagen y semejanza de Dios. Esta particularidad en el conjunto de la creación es la base de su dignidad teológica. Desde el punto de vista teológico, lo que hace digna a una persona no es su inteligencia, su moral, su naturaleza, su libertad o su capacidad de amar, su posición política o identidad religiosa, sino el hecho de ser imagen de Dios.

En el capítulo 8 del evangelio de Marcos, Jesús sana a un hombre ciego en Betsaida. Este pasaje nos muestra la sensibilidad de Jesús al tomar 
a la persona enferma de la mano, la aleja de la multitud curiosa, conversa con ella, la toca, usa recursos de la naturaleza, hace que la persona participe en el proceso de la cura. Jesús acoge, pregunta, oye, cura, valoriza la fe y la confianza. El rescate de la integridad y la dignidad de las personas es algo que Jesús practica en sus relaciones con las personas, sobre todo con las enfermas. Se enfrenta así a un sistema religioso y social que excluye a las personas enfermas, sin reconocer en ellas el valor que proviene de su propia condición humana.

En términos de enfermedad, el sanador en la cultura mediterránea del primer siglo está más preocupado por las relaciones sociales que por el padecimiento físico. El acto de la sanidad se enfoca más en la recuperación del estado de ser de la persona que en sus capacidades para actuar con normalidad. La pérdida de la salud no es tanto una cuestión biomédica como social, se trata de una devaluación del ser cuando la persona pierde al apoyo del entorno social o este deja de tener significado (Manila y Rohrbaugh, 1996).

Esto ayuda a comprender mejor la relación entre pecado y enfermedad una vez que el pecado significa una ruptura en las relaciones interpersonales, un desvío de las normas y los valores culturales. Así, el leproso no es solo alguien que padece una afectación física sino que se vuelve impuro, excluido de la comunidad. Los ciegos, cojos y quienes sufrían malformaciones en su cuerpo no tenían acceso a los espacios sagrados (Lev 21, 16-24). Por todo ello, las curaciones de Jesús están más en sintonía con los sanadores campesinos quienes ayudan a las personas a recuperar el lugar que ocupaban en la comunidad. El proceso de curación está relacionado con la práctica de la solidaridad y la lealtad hacia un sistema de creencias (Lc 13, 10-17).

La práctica sanadora de Jesús es un desafío que sigue vigente para las iglesias. Cuando visitamos casas, asilos y hospitales movidos solamente por el afán de la conversión de las personas no hay respeto por su dignidad y su integridad, no hay diálogo ni reconocimiento del ser de las personas, de sus verdaderas preocupaciones y necesidades. No se puede sacrificar la integridad de la persona por cualquier fin, ni siquiera el más elevado.

Sanar, salvar, humanizar es ponerse al servicio de la persona para que esta pueda realizar sus posibilidades existenciales. Esto pasa por el reconocimiento de la dignidad de la persona, la posibilidad de constituirse, de afirmarse, de construirse, de reconocerse como especie con derechos. La dignidad es la capacidad de afirmarnos como seres valiosos. Es en el ejercicio de la libertad donde el ser humano revela su dignidad. Jesús pregunta al ciego Bartimeo en otro pasaje de Marcos, “¿qué quieres que haga por ti?". No viene con la solución fabricada de antemano, dialoga y se coloca en el lugar de la persona enferma, intenta ayudarle a partir de su 
necesidad real y no desde algún pre-concepto. Cuando Jesús cura, realiza un acto terapéutico y salvífico.

\section{Salud y vida plena: una mirada ecoteológica}

Hablar de salud y vida plena hoy en día no es posible si no tomamos en cuenta que la salud humana está relacionada con la salud ambiental, con la salud del planeta. Hoy muchos dicen que nuestro planeta es un planeta enfermo y con esta imagen hacen alusión a la realidad trágica de la contaminación y el deterioro que sufre nuestra casa común que es la Tierra. Y ese desequilibrio está siendo causado justamente por la acción irresponsable de la humanidad. Por tanto, un planeta enfermo es imagen de una humanidad enferma. Como bien afirma el Papa Francisco en su encíclica Laudato si, no se puede comprender el deterioro ecológico sin el deterioro ético y cultural que lo acompaña (Francisco, 2015).

Un ejemplo de esta interconexión en todo el desequilibrio que vivimos es el cambio climático global. La concentración de gases de efecto invernadero, el uso intensivo de combustibles fósiles y la deforestación para uso de la agricultura son algunas de las principales causas del aumento de la temperatura del planeta en las últimas décadas. Ello intensifica otros fenómenos como las sequías, los huracanes y las inundaciones. Esto, a su vez, tiene un impacto sobre la agricultura afectando el sustento de vida de millones de personas las cuales padecen desempleo, hambre y escasez. Por otro lado, los calores y las nevadas extremos provocan la muerte cada año de miles de personas. Si la temperatura del mar continúa aumentando, continuarán desapareciendo especies marinas y se producirán alteraciones en los ecosistemas.

Richard Acosta, en su libro Dios, hombre, creación. Hacia una ecoteología biblica utiliza una imagen sugerente: el homo sapiens se ha vuelto homo virus. El ser humano único ser de la creación que puede admirar, escudriñar, estudiar, comprender, alabar la creación del gran Hacedor del universo y extasiarse con tan magnífica obra, muy por el contrario, como hijo inconsciente, en tan poco tiempo, se ha concentrado en aniquilarla y llevarla al límite de su resistencia. Tristemente, el Homo sapiens se ha transformado en Homo virus (Acosta, 2014, p. 14).

Les propongo entonces un segundo momento en nuestra reflexión para detenernos en esta dimensión ambiental de la salud.

En el griego del Nuevo Testamento, el verbo sozo se traduce como "sanar" y como "salvar", es decir, una persona sanada de alguna enfermedad es también una persona salva. Recuperar la salud es equivalente a obtener la salvación. En varias de las curaciones que Jesús realizó, utilizaba estas palabras: "Tu fe te ha salvado" (Lc 8, 48; 17, 19). Recibir la sanidad física es parte esencial de la experiencia de ser salvado. Por eso, es necesario plantearse nuevamente el significado de la salvación 
y sus consecuencias para nuestra vida presente y en medio de la crisis ambiental que vivimos. Ya no es posible seguir afirmando una salvación que solo afecta el espíritu humano, dejando fuera su corporalidad. Tampoco es posible seguir afirmando una salvación que solo sea para el ser humano sino que toda la creación de Dios también forma parte de esa experiencia de salvación.

En este sentido, recuperar la salud, recibir la salvación tiene que ver con la restauración de relaciones perdidas, con la reconstrucción del tejido de la vida, con el rescate de la dimensión ecuménica e inclusiva de la salvación, porque la salvación ocurre aquí y ahora, y afecta a todos los seres vivientes. Para cambiar el modo de relacionarnos necesitamos cambiar el modo de comprendernos. Por eso necesitamos una teología de la salvación que nos ayude en este camino de transformación de nuestro entendimiento y de nuestra conducta.

Esta teología de la salvación tendrá que ser necesariamente una ecoteología que permita redescubrir en la fe elementos ecológicos que favorezcan una sana y equilibrada interrelación entre Dios la humanidad y la creación. Esta teología requiere de un fundamento ético que presente la relación Dios-humanidad-creación como una relación de amor, de libertad y responsabilidad expresadas en una acción responsable con todos los seres vivos. Así el mensaje de la salvación puede otorgar el lugar adecuado y liberador a la naturaleza como creación, al ser humano como imago dei y a Dios como Creador. Es un mensaje salvífico que denuncia todo lo que esclaviza al ser humano y al resto de la creación (Castellón, 2012).

\subsection{La salvación del pueblo está en conexión con la renovación de toda la creación}

Desde las primeras páginas de la Biblia, se nos revela esta conexión entre vida, salud y salvación. Y también se revela que la vida es un entramado de relaciones entre todos los seres creados. Por tanto, si hablamos de salvar la vida estamos hablando de salvar la creación. La Biblia es clara en afirmar que el pecado humano produce una ruptura no solo con Dios y con el prójimo sino con todo lo creado. La consecuencia del pecado humano es muerte y destrucción de la vida; así mismo, la salvación-sanidad del ser humano trae consigo la restauración de la vida.

La historia del diluvio, en el libro del Génesis, ilustra esta realidad. Toda la creación es afectada por causa del pecado humano pero al final de la historia emerge, como señal de esperanza y continuidad de la vida, una nueva creación con la cual Dios establece un pacto de vida (Gn 7, 17 al 9, 17). Las plagas que sufren los egipcios, según el relato del libro del Éxodo, son producto de la opresión que mantiene el faraón sobre los esclavos. La opresión desencadena una serie de sufrimientos que afectan a las personas 
y a toda la tierra. Cuando el opresor reconozca su pecado y cambie su conducta entonces cesarán las calamidades. Cuando el opresor recuerde al pobre y desvalido, y le conceda la libertad entonces habrá esperanza para los esclavos, las plantas, los animales, la tierra (Ex 7, 8 al 11, 10).

La palabra hebrea traducida por "plaga" en el texto del Éxodo, debe ser traducida más bien como prodigio, señal, maravilla, un hecho asombroso que muestra el poder de Dios. La creación también sufre con las personas y se hace solidaria en esta liberación que Dios realiza. La creación no es solamente la obra de Dios sino que también participa de las obras que Dios realiza a favor de la liberación de los oprimidos.

De ahí que los problemas ambientales no puedan separarse de los problemas sociales. Las mismas políticas que degradan el medio ambiente también fundamental la injusticia social. Ellas presuponen la dominación, tanto de la naturaleza como de la humanidad, siempre obedecen a los intereses de los sectores poderosos y, mediante el control de la política y la economía, representan la imposición de estos intereses como si fuesen de todos (May, 2002).

Las imágenes de restauración del pueblo, tan comunes en los textos proféticos, establecen una clara conexión entre todos los seres vivos. La naturaleza no solo alimenta un lenguaje simbólico para expresar la experiencia de la salvación humana sino que la naturaleza misma experimenta la sanidad y la restauración junto con la humanidad. Del mismo modo en que el pecado humano arrastra consigo a toda la creación así la salvación del ser humano significa la salvación de todo lo creado.

En el exilio, el profeta Ezequiel reconoce a la tierra como sujeto de la salvación. El anuncio de la salvación se hace no solo al pueblo exiliado sino a la creación misma:

Escuchen el mensaje del Señor a las montañas, colinas, ríos y valles; a las ruinas despobladas y a las ciudades desiertas de Israel que han sido saqueadas por los pueblos vecinos ... Por lo tanto yo, el Señor, juro que los pueblos vecinos de ustedes se verán cubiertos de vergüenza. Ustedes, en cambio, montañas de Israel, estarán cubiertas de árboles grandes y con mucho fruto para mi pueblo Israel, que ya está a punto de regresar. Yo las voy a proteger, y haré que sean cultivadas y sembradas. Haré que aumente mucho el pueblo de Israel que vive allí. Las ciudades se llenarán de habitantes, y las ruinas serán reconstruidas (Ez 36, 1-12).

También el Segundo Isaías anuncia los tiempos de liberación para el pueblo desterrado. La creación participa de estas obras de salvación y comparte la alegría del pueblo en su regreso a la tierra deseada.

Así como la lluvia y la nieve bajan del cielo, y no vuelven allá, sino que empapan la tierra, la fecundan y la hacen germinar, y producen la semilla para sembrar y el pan para comer, así también la palabra que sale de mis labios no vuelve a mí sin producir efecto, sino que hace lo que yo 
quiero y cumple la orden que le doy. Ustedes saldrán de allí con alegría, volverán a su país con paz. Al verlos, los montes y las colinas estallarán en cantos de alegría y todos los árboles del campo aplaudirán (Is 55, 10-12).

\subsection{La creación es fuente de salud para el ser humano}

La creación no solamente comunica las obras de Dios sino que ella misma es fuente de salud/salvación para la humanidad. Veamos algunos elementos naturales que más allá del uso cotidiano que hacemos de ellos, se vuelven en sí mismos un mensaje acerca del cuidado de Dios para nuestra vida.

\section{Pan}

De la misma manera en que el agua, las codornices y el maná sustentaron al pueblo en su dura travesía por el desierto, así también el pan ha devenido signo de la fe y la esperanza cristiana. En las culturas bíblicas, comer es un gesto capital. En especial, el israelita se interesa más por el aspecto relacional de la comida (Sal 128). En la mesa la célula familiar toma conciencia de sí misma y discute las dificultades internas (Jc $19,4-8 ; 1 \mathrm{~S} 1,4-8)$. Alrededor de la mesa se establecen lazos de amistad, se comparten preocupaciones, se expresan los grandes deseos (Gn 18; 2 S 3, 20).

En el ambiente de las comidas Jesús define públicamente su opción por los excluidos y excluidas de su tiempo (Lc 7, 36-50) y compara el reino de Dios a un gran banquete donde todas las personas son aceptadas sin distinciones de ninguna clase (Lc 14, 16-24). Cuando Jesús se sienta a la mesa con los pecadores subvierte el orden social sacralizado, practica el compañerismo y cuestiona las verdades establecidas (Hoornaert, 1995). La mesa de Jesús es una práctica transgresora que busca la igualdad y la comunión entre las personas. Desde allí Jesús desafía la rigidez de las jerarquías, los privilegios y los exclusivismos.

Esta misma preocupación aparece en el apóstol Pablo cuando reprende a los cristianos más acomodados de Corinto por haber convertido la Cena del Señor en una escandalosa glotonería excluyente, donde los hermanos más pobres no alcanzaban a comer nada cuando se reunían a celebrar la eucaristía (1 Co 11). Así, aquellas reuniones, en vez de edificar lo que hacían era dañar la unidad del cuerpo de Cristo. La cena perdía su sentido al no ser una muestra de solidaridad y amor en el espíritu del sacrificio de Jesús por cada ser humano. El menosprecio por los pobres hacía del culto un instrumento del mal (v. 17) (Foulkes, 1996).

En la última cena Jesús recapitula su vida de servicio y se revela (se ofrece) como el que sirve (Jn 13). La mesa común crea entre los comensales una comunidad de existencia y Jesús convoca a los suyos alrededor de la mesa, ofreciendo los frutos del tiempo mesiánico: gozo (Mt 9, 5), perdón 
(Lc 7, 47), salvación (Lc 19, 5) y abundancia para la multitud hambrienta (Mt 14, 15-21). Jesús resucitado se hace también presente en la comidas de sus discípulos (Lc 24, 41; Jn 21; Hch 1, 4). La última cena no puede desvincularse de todas las comidas de Jesús donde aparece el conflicto entre aquel que sirve al pueblo y aquellos que se sirven a sí mismos.

El pan compartido es signo de la salvación, es una señal que remite a Cristo, a su cuerpo ofrecido por nuestra salud. Así, el pan que compartimos en memoria de Cristo es el pan que alimenta nuestra lucha por una sociedad donde todos puedan tener acceso al alimento. Sin el alimento necesario nuestro cuerpo se debilita, se enferma. El pan compartido en memoria de Jesús se vuelve señal de ese nuevo mundo donde no habrá injusticia ni hambre. La creación adquiere un valor salvífico porque por medio de ella satisfacemos nuestra necesidad de comer, obtenemos la salud, nuestros cuerpos son renovados y fortalecidos.

Pero el simbolismo del pan alcanza su mayor fuerza en el contexto de la cena pascual, de la eucaristía, del memorial de la vida, muerte y resurrección de Cristo. El pan y el vino simbolizan la vida toda del ser humano y del cosmos, es el fruto de la tierra y del trabajo de hombres y mujeres. Ione Buyst siente que ellos llevan en sí la fuerza, la energía, la creatividad, el gesto de la colaboración y la dedicación de la humanidad entera (Buyst, 1998).

La escasez de pan y vino nos hacen pensar en los males de la acumulación de bienes, la estructura económica que lleva a muchos al desempleo, el hambre y la pobreza (1 S 8, 10-18). El pan es signo de la subsistencia (Lc 11, 3), del alimento esencial, de la fuerza para seguir el camino. El vino provoca la fiesta y la alegría (Sal 104, 15). En las tradiciones semitas es símbolo del conocimiento y de la iniciación, alude también al sacrificio (Ex 29, 40) y la sangre (Dt 23, 14). Pan y vino simbolizan los grandes dones de Dios a la humanidad (Gn 27, 28; Mc 14, 22). Estos elementos están presentes en la comida diaria, calman el hambre y la sed, realzan la fraternidad y el placer de la convivencia (Pr 22, 9; Ct 1, 4). Ellos representan también los dones de los tiempos escatológicos (Pr 9, 1-5; Is 26, 6; Jer 31, 12; Mc 2, 22).

\section{Agua}

El agua es imprescindible para la vida. En su travesía por el desierto, el pueblo hebreo pudo calmar su sed bebiendo del agua de la roca. El agua que no escasea es señal de la abundancia en los tiempos mesiánicos. Jesús ofreció a la mujer samaritana el agua de vida, un agua que calma nuestra sed de afecto, de amor y de justicia. Es el agua que corre limpia y cristalina en el cauce del río de la vida que describe el libro del Apocalipsis en su capítulo 22, un río que nace en el trono de Dios y del Cordero. De igual modo, ese río de agua viva siempre está brotando del interior de la vida de quienes acogen la palabra de Jesús y la ponen en práctica. 
El agua es también señal de lavamiento y purificación. El agua es un agente purificador, limpia las superficies sucias, arrastra consigo las impurezas. Esta purificación es una experiencia que vivimos cotidianamente cuando tomamos un baño, cuando nos lavamos las manos antes de comer, cuando lavamos los platos o la ropa. Al caer la lluvia, el agua también purifica la tierra, limpia las calles, desintoxica un poco la ciudad de tanto polvo acumulado. Sin el agua es imposible la vida, la necesitamos para mantenernos limpios, para que el ambiente donde se desarrolla nuestra vida sea también un ambiente limpio.

Uno de los grandes males de las ciudades es la acumulación de basura y desechos de todo tipo. El mundo moderno es un mundo contaminado, hay lugares en el planeta donde la acumulación de desechos sobre los ríos apenas permite ver las aguas del propio río. Aquellas aguas que están en el planeta para purificarlo, para mantenerlo limpio de su contaminación están siendo invadidas de la mugre y el desperdicio que la humanidad arroja sobre ellas. Las aguas de la purificación se van convirtiendo en un excusado global, en una fosa pestilente donde las personas arrojamos todo lo que consumimos.

Desde tiempos antiguos, los pueblos y culturas han utilizado ritos de lavamiento y purificación. El pueblo judío practicaba bautismos de lavamiento y purificación. El libro de Levítico indica que todo contacto con algo o con alguien impuro requiere del posterior lavamiento de las vestiduras y del cuerpo de la persona que se ha contaminado con aquella impureza. Juan bautizaba en el río Jordán y su bautismo era un bautismo de purificación para el perdón de los pecados y para preparar el corazón de la gente ante la inminente llegada del mesías. Era un bautismo de conversión y preparación para recibir al mensajero del reino de Dios (Lc 3, 1-18).

Las iglesias mantuvieron este sentido de purificación en su práctica del bautismo. Ahora el bautismo es señal de la purificación de nuestros pecados. En el libro de los Hechos se nos cuenta que al final de su gran predicación en el día de Pentecostés, el apóstol Pedro invitó al pueblo al arrepentimiento y al bautismo en el nombre de Jesucristo para el perdón de sus pecados y así poder recibir el don del Espíritu Santo (Hch 2, 1447). ¿Y qué es lo que viene después del bautismo? Una vida consagrada y fiel al evangelio, un seguimiento permanente a Jesucristo, asumir como nuestro el proyecto de Dios para este mundo: la salvación, la paz con justicia, el amor solidario. Al igual que las aguas contaminadas, al igual que el mundo contaminado, una vida contaminada no es testimonio de la voluntad de Dios, no refleja lo que Dios quiere para su creación.

Otro de los significados que el bautismo tiene en las Escrituras es el nuevo nacimiento. El acto de sumergirse y de emerger del agua encuentra un paralelo con la muerte y la resurrección. Es entrar en el mundo caótico 
y desconocido que se oculta bajo las aguas para resurgir como nueva criatura. De este modo, el bautismo nos identifica con la experiencia de Jesús.

En la Biblia es recurrente el simbolismo de las aguas que sepultan lo viejo para que renazca lo nuevo. El diluvio, en el Génesis, cubrió toda la tierra, toda forma de vida pereció, y al cabo de cuarenta días, emergió un mundo nuevo. El Mar Rojo fue abierto en dos y el pueblo hebreo que escapaba de los egipcios cruzó por tierra seca en medio de las aguas. Cuando el ejército egipcio intentó alcanzar a los hebreos, el mar se volvió nuevamente sobre ellos y murieron. Pero el pueblo hebreo salió del mar, renació ese día a una vida nueva (Ex 14, 15-31).

En el libro de Josué encontramos el relato del cruce del río Jordán. Cruzar el Jordán era necesario para que Israel, después de muchos años de travesía por el desierto, tomara posesión de la tierra de Canaán. Del otro lado del río, Israel encontraría mejores territorios donde cultivar la tierra, desarrollar la cría de ganado y establecerse como pueblo. Para realizar el cruce del Jordán, un grupo de sacerdotes tomaron el arca del pacto del Señor y llegaron a la orilla del río. Cuando sus pies fueron mojados por las aguas, estas se dividieron y así el pueblo atravesó el Jordán en tierra seca. Cuando todo el pueblo hubo atravesado el río, los sacerdotes también lo atravesaron con el arca, y al salir ellos del río, las aguas volvieron a correr como antes. Josué mando tomar doce piedras del río y levantó un monumento en recordación de aquel día (Jos 3 y 4).

El bautismo como purificación y como nuevo nacimiento nos habla de una misma experiencia: la conversión, un nuevo comienzo, el dejar atrás la vida sin Cristo para comenzar a vivir la vida con Cristo. Esta vida nueva significa un giro radical de nuestro modo de ver y comprender la realidad, un cambio en nuestros valores, en nuestras prioridades. Nuestra vida se orienta ahora hacia los propósitos del reino de Dios.

Sin embargo, vivimos en medio de señales de muerte en un mundo contaminado. Atentamos constantemente contra la vida en esta creación buena de Dios. Toda forma de violencia, de maltrato, de indiferencia, de egoísmo, de injusticia, destruye la vida. Y todo proviene del mismo foco de maldad, de la misma fuente contaminante: el corazón humano desprovisto de la capacidad de amar a los demás como se ama a sí mismo. Pero sabemos que toda esta realidad de muerte es evitable, esta realidad se puede revertir. El bautismo es un pasaje del yo al nosotros, del egoísmo a la solidaridad, de una vida dominada por el pecado a una vida que enfrenta el pecado. Vivir consecuentemente nuestro bautismo es una poderosa señal de esperanza ante la actual destrucción de nuestro entorno natural.

\section{Árbol}

El tercer y último elemento natural que vamos a destacar es el árbol. Una de las parábolas de Jesús sobre el reino de Dios utiliza la imagen de la 
planta de mostaza (Mt 13, 31-32). Parte esencial del mensaje de la parábola es mostrar la conexión entre los personajes del texto. No es posible el árbol sin la tierra y sin que alguien siembre la semilla, no es posible que las aves puedan anidar si no hay un árbol con ramas. Si falta algún elemento el mensaje del reino estaría incompleto, pero no solamente el mensaje sino la manifestación misma del reino estaría incompleta.

Tanto al comienzo como al final de la Biblia encontramos la figura del árbol de la vida, primero en el jardín del Edén (Gn 2, 9), después en la plaza de la nueva Jerusalén en el libro del Apocalipsis (Ap 22, 1-2). En ambos lugares, el árbol de la vida ha sido colocado para alimento y curación de las personas y las naciones. El árbol de la vida está presente en el mundo creado por Dios y se relaciona con los demás seres vivos ofreciendo sus frutos y beneficios. El reino de Dios no solamente incluye en su proyecto de vida a todo ser viviente sino que es un espacio donde aprendemos a relacionarnos, a convivir, a coexistir de tal manera que ya no es posible vivir fuera de la relación con otras formas de vida. El reino de Dios no es el reino de la independencia, el individualismo y la violencia sino el reino de la interdependencia, la vida en comunidad y la paz.

En el libro de Daniel, capítulo 4, encontramos un relato que vamos a comparar con nuestra parábola de la semilla de mostaza. Nabucodonosor, rey de Babilonia, ha tenido un sueño extraño. Un árbol muy grande se levanta en medio de la tierra, su copa llegaba al cielo y se le podía ver desde cualquier lugar. Sus frutos y sus hojas eran tan abundantes que podían alimentar a todos. Las bestias del campo descansaban bajo su sombra, las aves hacían nidos en sus ramas y todo ser viviente dependía de aquel árbol. De repente, un ángel del cielo pronuncia una dura sentencia: el árbol debe ser cortado, sus frutos esparcidos, y quedará solamente el tronco y las raíces, y será sujetado a la tierra con cadenas, se volverá un animal y comerá la hierba del campo. Y todo esto sucederá para que las naciones sepan que el Dios altísimo tiene poder sobre los reinos humanos, que Dios puede convertir a la persona más humilde en gobernante de un pueblo.

Daniel comunica al rey el significado de aquel sueño. El árbol es el propio Nabucodonosor quien ha crecido y se ha hecho poderoso, y su dominio se extiende por toda la tierra. Pero Dios ha dictado sentencia contra el rey, será separado de la gente y vivirá como una bestia comiendo la hierba del campo hasta que reconozca que el Dios altísimo tiene poder sobre todos los reinos humanos. Si aún se preserva el trono del árbol con sus raíces es para dejar abierta la posibilidad de que el rey vuelva a ser lo que era antes si y solo si reconoce que Dios es quien tiene el poder. Por tanto, el rey debería actuar con justicia y no pecar más, deberá poner fin a su maldad y ocuparse de los pobres. Tal vez así el rey pueda seguir viviendo en paz y prosperidad. 
Este relato nos ayuda a no equivocar el camino que nos conduce al reino de Dios. Hay un árbol que expresa el poder de los reinos humanos, el poder que se construye sobre la base de la prepotencia, la dominación, la injusticia y la violencia. Y hay otro árbol que expresa el poder del reino de Dios cuyos frutos son la humildad, la justicia y la misericordia. Humildad, justicia y misericordia es lo que Dios pide de nosotros, esos son los ingredientes del reino (Mq 6, 8; Lc 18, 14).

De ahí que la señal del crecimiento en la parábola es una alerta contra el triunfalismo del crecimiento. La planta de mostaza ha crecido en verdad pero sigue siendo una hortaliza, un árbol pequeño, solo supera en tamaño a las demás hortalizas del huerto. De manera que el reino de Dios crece pero no para igualarse a los reinos de este mundo. El entorno donde crece la semilla del reino es más bien el entorno de lo pequeño, entre los pequeños se manifiesta el reino. No se trata de concentrar el poder en un árbol único cuya copa llega al cielo, se trata de hacer presente el poder de Dios en pequeñas plantas de mostaza que pueden crecer en todos los rincones del mundo. De modo que la fuerza transformadora del reino de Dios se haga presente en todo lugar pero no buscando grandeza y privilegios sino sirviendo, ofreciendo sus frutos humildemente.

El profeta Isaías anuncia la llegada de los tiempos mesiánicos por medio de una rama, un vástago que sale del tronco de un viejo árbol. Ese retoño se vuelve figura del mesías prometido, figura de los tiempos de salvación donde se hará justicia a los débiles y desamparados, y los malvados pagarán por sus crímenes. Serán tiempos en que habrá perdón, reconciliación y paz. Serán tiempos en que se podrá recuperar la armonía perdida entre todos los seres vivos, armonía ejemplificada en el texto por relaciones cordiales, no agresivas entre las personas y los animales. "Nadie hará daño en el monte santo", concluye el profeta, "porque la tierra será llena del conocimiento de Dios" (Is 11, 1-9).

$\mathrm{Al}$ igual que la planta de mostaza, este retoño es imagen de un mundo nuevo que está naciendo y que trae sanidad y salvación a quienes habitan la tierra. El pan que alimenta, las aguas que purifican y el árbol pequeño que se vuelve signo del reino de Dios son imágenes que alientan nuestros esfuerzos por el cuidado de la vida.

\section{Conclusión}

A manera de conclusión quisiera colocar algunos mensajes-desafíos:

- La salud y la enfermedad son parte de la realidad humana. Dios nos ayuda a convivir con las dificultades y las dolencias, nos llama a confiar en él. Dios puede transformar la flaqueza humana en poder. A veces la dolencia nos ayuda a ser humildes, la dificultad a veces fortalece el camino de la fe. La enfermedad puede ser tiempo de gracia y salvación. 
- Necesitamos comprender la salud en un sentido holístico, global, integrador. La salud implica bienestar físico, mental, social y ambiental. El aspecto religioso no debe ser el único factor de peso. La voluntad de Dios es que su creación tenga una vida digna, abundante en todos los sentidos. La salvación en la Biblia conlleva la necesidad de la salud integral de la persona.

- Ser una comunidad de sanación implica también denunciar aquellas estructuras sociales que distribuyen de manera injusta y desigual los recursos que pueden contribuir a la salud humana y ambiental.

- El evangelio nos llama a trabajar por la sanación del planeta. Tenemos la responsabilidad de cuidar de la vida en todas sus manifestaciones porque la vida es un entramado de relaciones, de interdependencia. Debemos aplicar la imagen paulina de que la iglesia es un cuerpo a la realidad que vivimos como creación: nuestro mundo es un cuerpo y cuando un miembro de ese cuerpo está enfermo, todos somos afectados. Trabajar por la sanidad del planeta es trabajar por nuestra propia salud, por nuestra propia salvación. La creación no es solamente fuente de salud para el ser humano sino que participa junto a la humanidad de aquellos eventos que puedan traer tanto el sufrimiento como la liberación.

Termino recordando uno de los sermones del teólogo Paul Tillich, titulado "También la naturaleza se lamenta por un bien perdido". Tillich afirma que el ser humano y la naturaleza se pertenecen mutuamente, comparten la gloria de la creación divina, comparten la tragedia de la destrucción pero comparten también la esperanza de la salvación. No hay salvación humana si no hay salvación de la naturaleza. El teólogo alemán nos recuerda que en la visión final del Apocalipsis, tanto la naturaleza como el ser humano se salvan de la esclavitud de la corrupción, el sufrimiento y la muerte dejarán de existir. Este tiempo futuro "es un símbolo que apunta hacia algo misterioso dentro de nuestro mundo actual, es decir, las fuerzas de la salvación" y es precisamente el mundo en su totalidad el que será salvado.

Entonces Tillich nos hace una pregunta: ¿todavía somos capaces de comprender lo que es un sacramento? En la medida que estemos alejados de la naturaleza tendremos más dificultades para responder afirmativamente a esta pregunta. Pero es a través de los sacramentos que la naturaleza participa en el proceso de la salvación.

Pan y vino, agua y luz, así como todos los grandes elementos de la naturaleza se hacen portadores de un sentido espiritual y de un poder salvador. Los poderes naturales y espirituales se unen -se vuelven a unir- en los sacramentos. Si su significación es viva para nosotros, los 
sacramentos impregnan tanto nuestro ser inconsciente como el consciente, se adueñan del fondo creador de nuestro ser. Constituyen el símbolo de la naturaleza y del espíritu, unidos en la salvación. ¡Comulgad, pues, con la naturaleza! Reconciliaos con ella ... Escuchadla en la quietud, y encontrareis su corazón. Y entonces el corazón de la naturaleza cantará la gloria de su fondo divino. Se lamentará con nosotros de la esclavitud de la tragedia. ¡Y nos hablará de la indestructible esperanza de salvación! (Tillich, 1968, p. 135).

\section{Referencias bibliográficas}

Acosta, Richard. Dios, hombre, creación. Hacia una ecoteología bíblica. Bogotá: Editorial San Pablo, 2014.

Buyst, Ione. Símbolos na Liturgia. Sao Paulo: Paulinas, Colecao Celebrar, 1998.

Castellón, José Marcos. Ecoteología. De cómo la ecología llega a ser problema teológico. Disponible en http://pastoralsocialgdl.files. wordpress.com/2012/05/ecoteologc3ada-1.pdf. Visitado el: 19 de abril. 2019.

Duarte, Marlin. Cuidado de la Salud Psicosocial y Espiritual en la vida cotidiana. En Santos, Hugo (Ed.). Dimensiones del cuidado y asesoramiento pastoral, Buenos Aires: Ediciones Kairos, Tomo II, 2012, pp. 93-101.

Foulkes, Irene. Problemas pastorales en Corinto. Comentario exegéticopastoral a 1 Corintios. San José: DEI, 1996.

Hoornaert, Eduardo. O movimento de Jesús. Petrópolis: Vozes. Colecao "Uma historia do cristianismo na perspectiva do pobre". Tomo I, 1995.

Manila, Bruce y Richard L. Rohrbaugh. Los evangelios sinópticos y la cultura mediterránea del siglo I. Comentario desde las ciencias sociales. Estella, Navarra: Editorial Verbo Divino, 1996.

May, Roy. Ética y Medio Ambiente. Hacia una vida sostenible. San José: DEI, 2002.

Papa Francisco. Carta Encíclica Laudato si. Sobre el cuidado de la casa común, Conferencia del Episcopado Dominicano, 2015.

Tillich, Paul. Se conmueven los cimientos de la tierra. Ediciones Ariel SA, 1968.

Zwetsch, Roberto. Saúde holística e métodos indígenas de cura em perspectiva teológica. En Estudos Teológicos, Vol. 43, No. 2, pp. 4459, 2003.

Amos López

lopez.amos70@gmail.com 